\author{
SERIES "RECENT DEVELOPMENTS IN PULMONARY INFECTIONS" \\ Edited by M. Woodhead and T. Schaberg \\ Number 6 in this Series
}

\title{
Microbial investigation in ventilator-associated pneumonia
}

\author{
M. loanas*, R. Ferrer" ${ }^{\#}$ J. Angrill", M. Ferrer", A. Torres
}

Microbial investigation in ventilator-associated pneumonia. M. Ioanas, R. Ferrer, J. Angrill, M. Ferrer, A. Torres. (C) ERS Journals Ltd 2001.

ABSTRACT: Ventilator-associated pneumonia (VAP) is a serious infectious condition in intensive care unit (ICU) patients, currently related to a high mortality rate. Therefore, this complication of mechanical ventilation requires a prompt diagnosis and adequate antibiotic treatment. The detection of the causative organism is imperative for guiding an appropriate therapy as there is strong evidence of the adverse effect of inadequate empirical treatment on outcome. The major difficulty of the microbial investigation is to obtain the sample from the lower respiratory tract, mainly because of the potential contamination with upper airways flora, which may result in a misinterpretation of the cultures.

Microbial investigation in VAP is based on the culture of samples obtained from lower respiratory tract by noninvasive or invasive methods. The most common techniques of sampling are the endotracheal aspirate (ETA), which is considered a noninvasive method, the protected specimen brush (PSB) and the bronchoalveolar lavage (BAL), both being invasive methods of investigation. The latter were designed as an attempt to avoid the colonizing flora of the upper airways. The best of these diagnostic approaches is still controversial. In terms of outcome, there is strong evidence that the impact of both invasive and noninvasive methods seems to be similar. In terms of cost, however, the endotracheal aspirate is less expensive compared to BAL or PSB. On the other hand, invasive methods could be particularly beneficial in patients who are not responding to the initial empirical antibiotic treatment.

The rationale for the quantitative culture of the respiratory samples is to differentiate between infection and colonization of lower airways, because the bacterial colonization is a frequent event in mechanically ventilated patients. The thresholds currently employed for the diagnosis of the pneumonia are the following: ETA samples, $\geqslant 10^{5}-10^{6}$ colony forming units (cfu) $\cdot \mathrm{mL}^{-1}$; PSB samples, $\geqslant 10^{3} \mathrm{cfu} \cdot \mathrm{mL}^{-1}$; and BAL samples, $\geqslant 10^{4} \mathrm{cfu} \cdot \mathrm{mL}^{-1}$.

Intending to provide a practical approach to the issue, the present manuscript reviews the available noninvasive (blood culture, endotracheal aspirate) and invasive (protected specimen brush, bronchoalveolar lavage, blinded methods and lung biopsy) techniques used for the diagnosis of ventilator-associated pneumonia.

Eur Respir J 2001; 17: 791-801.
Institut Clinic de Pneumologia i Cirurgia Toracica, Hospital Clinic y Provincial, Barcelona, Spain, *Institutional National de Pneumoftiziologie "Marius Nasta", Bucharest, Romania. ${ }^{\#}$ Unidad de Cuidados Intensivos, Hospital de Parc Tauli, Sabadell, Barcelona, Spain.

Correspondence: A. Torres

Servei de Pneumologia

Institut Clínic de Pneumologia i Cirurgia Toracica

Hospital Clinic i Provincial

Villarroel 170

08036 Barcelona

Spain

Fax: 34932275454

Keywords: Bronchoalveolar lavage microbiology

protected specimen brush

pulmonary infections

ventilator-associated pneumonia

Received: July 72000

Accepted after revision October 32000
The diagnosis of pneumonia in mechanically ventilated patients is a challenge for the clinician, since the classic clinical presentation is variable and other causes of fever and chest infiltrates may occur in these patients. The high mortality rate of (ventilator-associated pneumonia (VAP), exceeding 50\% according to some authors [1, 2], requires a rapid initiation of the appropriate antibiotic treatment. Several studies have shown that an inadequate antibiotic treatment is related to a poor prognosis [3]. By contrast, antibiotic overtreatment may select multiresistant organisms such Pseudomonas aeruginosa or Acinetobacter calcoaceticus [4]. Thus, it is important to provide reliable information on the causative agent and it's susceptibility to antibiotics for guiding treatment and preventing the selective pressure of some antibiotics.

Over the last decade, continuous efforts have been made in order to develop optimal techniques for

Previous articles in this series: No. 1: Hammerschlag MR. Chlamydia pneumoniae and the lung. Eur Respir J 2000; 16: 10011007. No. 2: Ewig S, Schäfer H, Torres A. Severity assessment in community-acquired pneumonia. Eur Respir J 2000; 16: 1193-1201. No. 3: Nicod LP, Pache J-C Howarth N. Fungal infections in transplant recipients. Eur Respir J 2001; 17: $133-140$. No. 4: Jones AM, Dodd ME, Webb AK. Burkholderia cepacia: current clinical issues, environmental controversies and ethical dilemmas. Eur Respir J 2001; 17: 295-301. No. 5: Rook GAW, Seah G, Ustianowski A. M. tuberculosis: immunology and vaccination. Eur Respir $J$ 2001; 17: 537-557. 
obtaining appropriate respiratory samples. The main problems in the interpretation of the results are the antibiotic treatment received before sampling and the upper airways colonization, both resulting in possible misinterpretation of culture samples. Microbiological investigation in VAP consists basically of culturing samples from the lower respiratory tract obtained by noninvasive or invasive methods. The latter were designed to avoid upper airways colonization. Despite their potential advantage, there is an ongoing controversy about their operative value when compared to noninvasive methods. Quantitative culture of the respiratory samples may help in a better differentiation between infection and colonization of lower airways, which is a frequent event in mechanically ventilated patients.

In terms of outcome, the impact of both invasive and noninvasive methods seems to be similar. However, those patients who are not responding to initial empirical antibiotic regimens could have an additional benefit from the use of invasive techniques to diagnose VAP. Randomized studies comparing the two types of techniques are currently recommended to answer these questions.

\section{Bacterial pathogens associated with ventilator-associated pneumonia}

The most comprehensive approach concerning the micro-organisms responsible for the hospital-acquired pneumonia (HAP) and particularly for VAP is the classification of the American Thoracic Society (ATS) [5]. This approach is useful for the initial empirical antibiotic treatment.

The spectrum of potential pathogens can be classified according to three variables: 1) severity of pneumonia (mild-to-moderate or severe); 2) presence of specific host or therapeutic risk factors; and 3) early or late onset of pneumonia ( $>$ or $<5$ days after admission to the hospital). Accordingly, patients can be classified into three groups: 1) patients without unusual risk factors who present with mild-to-moderate HAP with onset at anytime during hospitalization or severe HAP with early onset; 2) patients with specific risk factors who present with mild-to-moderate HAP occurring any time during hospitalization; 3) patients with severe HAP, either of early onset with specific risk factors or of late onset.

Bacterial agents causing nosocomial pneumonia in patients from ATS Group 1 are defined as "core organisms" and include: enteric Gram-negative bacilli (Enterobacter spp, Escherichia coli, Klebsiella spp, Proteus spp, Serratia marcescens), Haemophilus influenzae, Streptococcus pneumoniae and methicillin sensitive Staphylococcus aureus. Organisms related to ATS Group 2 pneumonia include those of ATS Group 1 but also anaerobes, Legionella pneumophilia, methicillin resistant $S$. aureus (MRSA) and $P$. aeruginosa. In ATS Group 3 pneumonia, "core organisms" are often isolated but additional pathogens like $P$. aeruginosa, Acinetobacter spp. and methicillin resistant $S$. aureus are also frequent. Patients belonging to this category are at risk of being infected with potentially multi- resistant organisms $[1,6-8]$. In mechanically ventilated patients, VAP is polymicrobial in $\sim 40 \%$ of cases.

Independent of the onset period, there is a panel of risk factors associated to a specific causative agent. The risk factors related to pneumonia by $P$. aeruginosa are prior antibiotic therapy, corticosteroids, prolonged mechanical ventilation, previous hospitalization, advanced chronic lung disease and severe bronchiectasis. Pneumonia with L. pneumophilia may occur in patients with prolonged corticosteroids therapy. $S$. aureus is isolated in $20-40 \%$ of cases $[1,9,10]$. Pneumonia caused by $S$. aureus occurs in patients with coma, head trauma, diabetes mellitus and renal failure [10]. The anaerobes are more frequently associated with abdominal surgery and with aspiration. Finally, it is important to point out that TROUILLET et al. [11] have reported that $>7$ days of mechanical ventilation and prior broad antimicrobial therapy are the two main risk factors for developing VAP with multiresistant Gramnegative pathogens.

Another approach of the infections acquired in the ICU considers three types of infection: primary endogenous, secondary endogenous and exogenous [12]. These different patterns have specific microbial profiles and can be distinguished only by surveillance cultures in all intubated patients admitted in ICU. VAP that occurs early after ICU admission is usually of primary endogenous nature. That means that the patient carried micro-organisms at the time of ICU admission. The responsible organisms are more likely to be community acquired pathogens like $S$. pneumoniae, $H$. influenzae or methicillin sensitive $S$. aureus. The secondary endogenous infection has late onset and occurs in patients colonized with bacteria acquired in ICU $(P$. aeruginosa, Acinetobacter spp., MRSA). Finally, the exogenous infection refers to VAP which occurs in patients without previous bacterial colonization and the microbial profile is similar to the secondary endogenous infection.

\section{Reasons to perform microbial investigation}

The clinical difficulties in assessing VAP in mechanically ventilated patients require more reliable tools for both diagnosis and follow-up. In addition, the evidence concerning the emergence of the resistant strains associated with the selective pressure of some antibiotics advise a very careful selection of the antibiotic regimens.

The bacteriological investigation of the respiratory samples prior to the initiation of the empirical antibiotic treatment appears to be of extreme usefulness. Several studies have shown that an inadequate antibiotic treatment is related to a poor prognosis [3, 13]. The isolation of the causative organism and the investigation of the susceptibility to antibiotics may allow a more appropriate and adjusted treatment with potential benefits for the patient as well as for the antibiotic policy of the hospital. Nevertheless, the microbial investigation presents two major inconveniences in mechanically ventilated patients: 1) prior antibiotic treatment, which is very frequent in ICU patients and may explain the false-negative results; and 
2) the upper and lower airways colonization, which is a cause of false-positive results.

Several means to avoid contamination of the lower respiratory samples by upper airways flora have been proposed: 1) the use of invasive methods for collecting samples from the site of infection (bronchoscopy, biopsy); 2) the use of protected devices for avoiding contamination of the sample with upper airways flora. In addition, quantitative cultures of the sample establishing a specific threshold of colony forming units (cfu) for differentiating between infection and colonization of the airways are recommended. All methods to obtain good quality respiratory samples have been extensively investigated and a debate exists about which is the most convenient one, in terms of cost-effectiveness and diagnostic yield.

\section{Noninvasive diagnostic methods}

\section{Blood culture}

The rate of positive blood culture in VAP ranges $8-20 \%[5,14,15]$. Some studies report that, in critically ill patients, bacteraemia is not always related to a pulmonary infection and up to $50 \%$ of the patients with positive blood culture may have an additional source of infection $[15,16]$. In a recent study, LuNA et al. [17] pointed out that blood cultures in patients with VAP are useful to suspect and identify another simultaneous infection when the micro-organism isolated in blood does not coincide with the micro-organism isolated in respiratory secretions.

\section{Endotracheal aspirate}

Endotracheal aspirate (ETA) is used frequently as a diagnostic method in intubated patients with suspicion of pulmonary infection, because of its simplicity and minimal training required. Similar to sputum samples, cytological examination of an ETA specimen with a large number of leukocytes is likely to provide an accurate microbiological result (table 1).

The qualitative culture of ETA usually identifies the same pathogens as the invasive tests (i.e. protected specimen brush; PSB), but frequently, the culture also contains other nonpathogenic organisms, resulting in

Table 1. - Criteria for the assessment of a good quality respiratory sample in ventilator-associated pneumonia (VAP) and recommended threshold for the quantitative culture to distinguish between colonization and infection

\begin{tabular}{lccc}
\hline & ETA & PSB & BAL \\
\hline Neutrophils & $>25$ & $>50 \%$ & $77-82 \%$ \\
SEC & ND & $<1$ & $<1 \%$ \\
ICO & ND & ND & $\geqslant 5 \%$ \\
Quantitative culture & $\geqslant 10^{5}-10^{6}$ & $\geqslant 10^{3}$ & $\geqslant 10^{4}$ \\
threshold $\mathrm{cfu} \cdot \mathrm{mL}^{-1}$ & & & \\
\hline
\end{tabular}

Data are presented as absolute number per field, or percentage of cell count. ETA: endotracheal aspirate; PSB: protected specimen brush; BAL: bronchoalveolar lavage; SEC: squamous epithelial cells; ND: no data.
Table 2. - Ranges of sensitivity and specificity for endotracheal aspirate (ETA), protected specimen brush (PSB) and bronchoalveolar lavage (BAL) in the diagnosis of ventilator-associated pneumonia (VAP)

\begin{tabular}{llll}
\hline & ETA & PSB & BAL \\
\hline Sensitivity \% & $38-100$ & $33-100$ & $42-93$ \\
Specificity \% & $14-100$ & $50-100$ & $45-100$ \\
\hline
\end{tabular}

ETA: endotracheal aspirate; PSB: protected specimen brush; BAL: bronchoalveolar lavage.

a low positive predictive value of this test. On the other hand, a sterile ETA culture makes the diagnosis of VAP very unlikely, unless the patient has been previously treated with antibiotics [18].

Quantitative culture of ETA may avoid these false positive results, but also provides controversial results, depending on the bacterial load, duration of ventilation and prior antibiotic treatment. The sensitivity ranges $38-100 \%$, while specificity ranges $14-100 \%[19,20]$ (table 2). Using a threshold of $10^{5}-10^{6} \mathrm{cfu} \cdot \mathrm{mL}^{-1}$, the sensitivity appears to have a narrower range (50-70\%) as well as specificity $(70-85 \%)[18,21]$ (table 1$)$. Comparing the outcome of patients, two studies came to the conclusion that there are no differences between ETA and invasive bronchoscopic methods (PSB and BAL) in terms of mortality, ICU stay and duration of mechanical ventilation [22, 23].

Detection of the antibody coating bacteria has been developed in an attempt to identify the difference between colonization and infection of the lower respiratory tract. In addition, the detection of elastin fibres has been proposed as a method for revealing the lung parenchyma destruction caused by pneumonia. The detection of both antibody coating and elastin fibres in the ETA are neither sensitive nor specific [24, 25], so they are not recommended for the routine diagnosis of VAP.

\section{Invasive diagnostic methods}

\section{Bronchoscopic techniques}

Fibreoptic bronchoscopy is a safe and accurate technique for the diagnosis of various pulmonary lesions. It's usefulness has been extended to the collection of lower airways secretions from the site of presumed infection. An additional benefit is the by-passing of the upper airways which are usually colonized by potential pathogenic micro-organisms (PPMs), especially in mechanically ventilated patients, leading to a potential misinterpretation of the cultures.

During the last two decades, these so-called invasive techniques have been extensively used for diagnosing HAP and particularly VAP. The attempts to improve the yield of these techniques have resulted in the development of methods such as PSB and bronchoalveolar lavage (BAL). Furthermore, the quantitative culture of the samples obtained by these methods allows a better differentiation between colonization and infection. 
In mechanically ventilated patients, fibreoptic bronchoscopy is performed through the endotracheal tube, so the inner bore of the endotracheal tube should be wide enough to permit the progression of the bronchoscope. Patients should be sedated and paralysed to allow an effective ventilation and to prevent bronchial mucosa damage during this procedure. For these reasons, local anaesthesia is not necessary in mechanically ventilated patients, thus preventing the inhibitory effects on bacterial growth when the drug is instilled into the airways. Additional recommendations and ventilatory parameter adjustments for performing bronchoscopy in mechanically ventilated patients are summarized in table 3.

Protected specimen brush. The PSB technique has been available for almost $20 \mathrm{yrs}$ for the diagnosis of pneumonia [26]. The technique has been refined for VAP, but the method remains basically unchanged. The PSB consists of a double telescoping catheter containing a metallic brush within the inner cannula. The technique involves positioning the bronchoscope next to the orifice of the sampling area and advancing the PSB catheter $3 \mathrm{~cm}$ beyond the fibreoptic bronchoscope to avoid collection of pooled secretion on the catheter tip. An inner cannula is protruded to eject a distal polyethylene glycol plug into the airway and the catheter is advanced to the desired subsegment. If purulent secretions are visualized, the brush is rotated into them. After sampling, the brush is retracted into the inner cannula and this one into the outer cannula, and the catheter is removed from the bronchoscope.

A small quantity of brushed secretions should be used for direct examination after staining by MayGrünwald Giemsa and Gram methods, which facilitates the evaluation of the quality of the sample [27] (table 1).

After wiping the inner cannula with $70 \%$ alcohol and cutting the brush with sterile scissors, the brush is placed in $1 \mathrm{~mL}$ of dilutant and immediately submitted for quantitative bacterial culture. The standardized procedure of PSB in VAP is shown in table 4 [28]. These recommendations have proved to be useful for reducing the rate of false-positive and false-negative results.

The volume retrieved is $\sim 0.001 \mathrm{~mL}$ (range $0.01-$ 0.001 ) of lower respiratory secretions and dilution into

Table 3. - Additional recommendations and ventilatory parameter adjustments during fibreoptic bronchoscopy through endotracheal tube

Insert a connection between the endotracheal tube and the the ventilator tubing to slide the fibreoptic bronchoscope.

Set $\mathrm{F}, \mathrm{O}_{2}$ at $100 \%$ and remove positive end-expiratory pressure, except in very severe respiratory failure.

Increase respiratory frequency and decrease tidal volume. Increase per cent inspiratory time.

Lubricate the fibreoptic bronchoscope to facilitate its slippage through the endotracheal tube.

After the bronchoscopic procedure, return all ventilatory parameters to their initial values and keep $\mathrm{FI}_{1} \mathrm{O}_{2}$ at $100 \%$ for $\geqslant 1 \mathrm{~h}$.
Table 4. - Methodology of protected specimen brush (PSB) in mechanically ventilated patients

\section{Step Procedure}

1 Position the tip of the bronchoscope close to the segmental area corresponding to radiographic infiltrates.

2 Advance the PSB $3 \mathrm{~cm}$ out of the distal tip of the bronchoscope.

3 Push the inner cannula of the PSB to eject the polyethylene glycol plug.

4 Wedge the brush in the subsegmental area or sample secretions if these are visualized.

5 Retract the brush into the inner cannula and the inner cannula into the outer cannula, and remove the PSB from the bronchoscope

6 Once the PSB is out of the bronchoscope, the distal portion of the inner cannula is wiped with $70 \%$ alcohol solution.

7 The brush is advanced and cut with sterile scissors into a sterile solution containing $1 \mathrm{~mL}$ of Ringer's lactate or saline.

8 The tube with the PSB and Ringer's lactate or saline solutions is submitted immediately to the microbiology laboratory for processing.

Data from ref [28].

the holding medium increases the dilution of the culture plate by 100-1,000-folds. Quantitative bacterial cultures of PSB allow the distinction between colonization and infection. Quantitative cultures represent serial dilutions of the respiratory samples. The colony counts are calculated by the number of colonies visible on the agar plate in relation to the dilution and inoculation factors. The cut-offs for quantitative culture results were established by relating colony counts known to be present in sputum samples of pneumonia patients to the estimated amount of respiratory secretions retrieved by the technique. Thus, it should be noted that the quantitative culture technique is based on rough inferences rather than exact measurements. For PSB, the currently accepted threshold is $10^{3} \mathrm{cfu} \cdot \mathrm{mL}^{-1}$. Growth $\geqslant 10^{3} \mathrm{cfu} \cdot \mathrm{mL}^{-1}$ is considered significant for infection (table 1) and corresponds to an initial concentration $10^{5}-10^{6}$ bacteria $\cdot \mathrm{mL}^{-1}$ in the retrieved secretions.

The plugged double-lumen catheter of the PSB technique offers the advantage of a minimal risk of contamination at the price of a very small area of sample collection. The usefulness of PSB has been extensively investigated in both mechanically ventilated and nonmechanically ventilated patients [16, 18, 29-36], most of the studies reporting reasonable results in diagnosing VAP. Sensitivity ranges $33-100 \%$ and specificity $50-100 \%$ (table 2 ). This variability is related to the type of population studied, the prior antibiotic treatment and the type of the gold standard used. Most studies show $<40 \%$ false-negative results. There are several explanations for these findings. First is the lack of standardization of the sampling technique. It has been suggested that sampling only the segment showing purulent secretions results in an increase in sensitivity [26] but histological studies [37, 38] report that VAP is a multifocal process; therefore a broad sampling 
technique appears to be more appropriate. Prior antibiotic therapy is another cause of false-negative results. MONTRAVERs et al. [39] reported that antibiotics can sterilize the respiratory samples collected by PSB after only 3 days of effective treatment. A recent histological study has confirmed that the sensitivity of any sampling technique and the bacterial burden of the lung are both dramatically decreased by the initiation of the antibiotic treatment [27]. This effect is less evident when the antibiotics are ineffective against the causative micro-organisms [40].

When sampling has been performed during an early stage of infection, it is likely to provide borderline results. This finding should not hinder the initiation or continuation of the antibiotic treatment. DREYFUSS et al. [41] reported that some of the borderline cultures (i.e. $10^{2}-10^{3} \mathrm{cfu} \cdot \mathrm{mL}^{-1}$ ) evolved into positive culture (above the threshold), suggesting that first sampling has been performed in an early stage of infection. The variability of the technique may be another source of false-negative results. Two studies [42, 43] have found that a repeated PSB sampling in the same segmental area had a clear degree of variability, with $14 \%$ of culture spreading above and below the $10^{3} \mathrm{cfu} \cdot \mathrm{mL}^{-1}$ threshold in one study [42] and $40 \%$ of spreading in the other [43]. Finally, a bacterial bronchiolitis without pneumonia could also provide a false-negative result. Although the bacterial level is rather low, this condition requires antibiotic treatment. Recent post mortem studies on the histology of VAP [37, 38] have reported a significant number of cases of bacterial bronchiolitis without pneumonia.

The overall rate of false-positive results is $\sim 30 \%$. The variability of the technique could provide also false-positive results. MARQUETTE et al. [42] reported that $60 \%$ of patients had PSB results that varied by more than one log unit when five PSB samplings were performed in the same patients and site. The bacterial colonization of the lower airways is frequent in patients with chronic obstructive pulmonary disease (COPD), bronchiectasis or prolonged antibiotic treatment, resulting in false-positive results of the sample obtained by PSB. TORRES et al. [44] found a specificity of $70 \%$ of PSB in mechanically ventilated patients without pneumonia and with prior antibiotic treatment. These findings are consistent with post mortem studies which showed that cultures of lung tissue obtained by biopsy were frequently positive in the absence of histological pneumonia [37].

Bronchoalveolar lavage. Besides it's usefulness in interstitial diseases and immune-compromised patients, BAL has proven to be an interesting diagnostic tool for the diagnosis of VAP. Quantitative cultures of the samples retrieved by protected and nonprotected bronchoscopic BAL appear to provide a good diagnostic yield.

In intubated patients, the bronchoscope is advanced through the endotracheal tube distally into a subsegmental bronchus (usually a third- or fourth-generation bronchus) until the airway is occluded proximally. As stated previously, patients are sedated and paralysed during the procedure, thus avoiding the need for local anaesthesia. A volume of sterile saline is instilled and then gently aspirated. Although there is no consensus about the total volume to be instilled, it appears that at least $100 \mathrm{~mL}$ are required to retrieve secretions from the periphery of the subsegment, with a range 100$240 \mathrm{~mL}$ [28, 45]. The sampling area is selected based on the correspondent area of the infiltrate on chest radiograph or by the visualization of a subsegment containing purulent secretions. Additional protected systems have been designed in order to avoid contamination of the retrieved BAL fluid. These methods are considerably more expensive since they involve catheters that are inserted into the bronchoscope channel, in addition to the rest of the equipment used in performing conventional BAL [46].

Although the returned volume may range $5-70 \%$ of the total volume instillated, generally $5 \mathrm{~mL}$ of the retrieved BAL fluid are adequate for microbiological and cytological examination. Microscopic analysis after May-Grünwald Giemsa and Gram stain allows a rapid evaluation of cell count and differential percentage of cells containing intracellular organisms, percentage of epithelial cells and direct visualization of organisms including Pneumocystis carinii. As a general rule, the presence of $>1 \%$ squamous epithelial cells suggests oropharyngeal contamination. Quantitative bacterial cultures of BAL samples facilitate the differentiation between colonization and infection. For BAL, the currently accepted threshold is $\geqslant 10^{4} \mathrm{cfu} \cdot \mathrm{mL}^{-1}$ for defining infection (table 1).

The 10-fold greater cut-off compared to PSB is based on the theory that BAL retrieves 5-10 times more organisms than the PSB. Routine cytological analysis and evaluation for opportunistic pathogen are recommended in case of immunosupression. Table 5 summarizes the BAL procedure [28]. The sensitivity and specificity of BAL vary widely among different studies depending mainly on prior antibiotic treatment, type of population studied and reference test employed. The sensitivity of the BAL method in patients with VAP ranges $42-100 \%[46,47]$. Specificity reported by these studies also has a wide range of variability with mean $82 \%$ (table 2). The explanation for the false-positive and false-negative results of BAL is the same as for PSB technique.

Complications of the bronchoscopic methods. The side effects of the bronchoscopic techniques can be divided as follows: 1) events inherent to the use of fibreoptic bronchoscope which will not be discussed in this paper; 2) events directly attributable to PSB or BAL.

PSB may cause bleeding, particularly in patients with renal failure and coagulopathies, and sometimes pneumothorax $[24,33,48]$. The complications of BAL include declines in arterial oxygen tension $\left(\mathrm{Pa}, \mathrm{O}_{2}\right)$, slight rises in arterial carbon dioxide tension $\left(\mathrm{Pa}_{\mathrm{a}}, \mathrm{CO}_{2}\right)$, fever, transient worsening in pulmonary infiltrates, sepsis-like effect (accounted to a bacterial translocation from alveoli to the systemic circulation) [49], arrhythmia and, rarely, pneumothorax, haemoptysis, exacerbation of respiratory failure, and transient increase in lung vascular permeability [50]. The most important side effects are the alterations in blood gases which depend on the type of lavage used (conventional BAL 
Table 5. - Methodology of bronchoalveolar lavage (BAL) in mechanically ventilated patients

\begin{tabular}{lc}
\hline Step & Procedure \\
\hline 1 & $\begin{array}{c}\text { Position the tip of the bronchoscope close to the seg- } \\
\text { mental area corresponding to radiographic infiltrates. }\end{array}$ \\
2 & $\begin{array}{c}\text { Instil } 3 \text { aliquots of } 50 \mathrm{~mL} \text { or } 5 \text { aliquots of } 30 \mathrm{~mL} \\
\text { saline. }\end{array}$ \\
3 & $\begin{array}{c}\text { After the injection of each aliquot, gently aspirate } \\
\text { through the suction channel. }\end{array}$ \\
4 & $\begin{array}{c}\text { Keep the first aliquot for separate analysis. } \\
\text { Pool the remaining aliquots in a sterile container and } \\
\text { submit them to the laboratory for microscopy and } \\
\text { microbiological analysis. }\end{array}$ \\
\hline
\end{tabular}

Data from ref [28].

or protected BAL) and the amount of liquid instilled (ranging between $50 \mathrm{~mL}$ in mini-BAL and $150 \mathrm{~mL}$ in conventional $\mathrm{BAL}$ ). Two studies reported a mean reduction of $20 \%$ in $\mathrm{Pa}_{2} \mathrm{O}_{2} /$ inspired oxygen fraction $\left(F \mathrm{I}, \mathrm{O}_{2}\right)$ ratio immediately after bronchoscopy, 5 and $24 \mathrm{~h}$ later $[16,51] . \mathrm{Pa}_{1} \mathrm{CO}_{2}$ values increased transiently ( $7 \mathrm{mmHg}$ on average). The authors did not find any change in haemodynamic parameters (arterial pressure, heart rate, cardiac index) after BAL.

Transbronchial biopsy. Transbronchial biopsy (TBB) has been used as a valuable diagnostic tool in sarcoidosis, lymphangitic carcinomatosis, diffuse opportunistic infections, and immune-compromised patients with pulmonary infiltrates. There are few data on the usefulness of TBB biopsy in mechanically ventilated patients with pneumonia, mainly because this technique is rather unusual for diagnosing VAP. The major inconvenience relies on the small size and uncertain representativeness of the tissue specimens. There is a statistically significant association between the specific diagnosis of infection and a greater number of alveoli contained in the biopsy specimen [52]. The findings reported by a study comparing TBB and open lung biopsy (OLB), both performed in the same patients, revealed a diagnostic yield of $94 \%$ of OLB versus $59 \%$ for TBB [53].

The fibreoptic bronchoscope is placed into the optimal subsegment allowing the best approach of the lesion. The forceps are opened, advanced $1-2 \mathrm{~cm}$ or until resistance, and then closed and gently retracted into the bronchoscope. The forceps should cut, not tear, the lung parenchyma. A total of 5-6 biopsy specimens are required for the peripheral lesions. The pieces of tissue are removed with a toothpick, transferred to a specimen jar containing formalin, and sent to laboratory.

Pneumothorax [54, 55] (due to biopsy of visceral pleura) and minor haemorrhage [53] are not infrequent. Massive haemorrhage has also been described as a possible, but not common, complication. However, in patients with limited pulmonary function and coagulation abnormalities, these complications should be taken into account. Because of the potential serious complications and the limited additional diagnostic yield (compared to other bronchoscopic procedures), the TBB should be considered as a second line diagnostic procedure in VAP.

\section{Nonbronchoscopic techniques}

Blinded invasive methods. In order to avoid the inconveniences related to fibreoptic bronchoscopy, such as high cost, side effects and required experience, alternative methods of sampling the lower respiratory tract in patients with suspicion of pneumonia have been designed. The most common are blinded bronchial sampling (BBS), mini BAL and blinded sampling with several different protected brushes (BPSB).

In BBS the catheter is advanced blindly in a distal bronchus and the secretions are aspirated without instilling additional fluid. A minimal recovered volume of $1-2 \mathrm{~mL}$ is required. For protected mini-BAL, a single-sheathed, $50 \mathrm{~cm}$, sterile, plugged telescoping catheter is used for instillation of $20-150 \mathrm{~mL}$ of fluid of lavage. Some studies on mini-BAL [56] have used a telescoping catheter with an additional device that allows to blindly direct the catheter toward the affected area; this type of catheter is not commercially available in present. The BPSB involves a sterile brush which is protected from contamination, similar to the PSB technique. Samples obtained by blinded procedures also require quantitative cultures. The accepted cut-off for distinguishing pneumonia of colonization is $\geqslant 10^{3}-$ $10^{4} \mathrm{cfu} \cdot \mathrm{mL}^{-1}$.

There is no clear standardization concerning the methodology of the blinded invasive procedures. Nevertheless, the sensitivity reported by several studies [7, 35, 38, 43, 48, 56-60] ranged $74-97 \%$ for BBS, $63-100 \%$ for mini-BAL and $58-86 \%$ for BPSB. Specificity appears to be similar to fibreoptic bronchoscope techniques (PSB and BAL) and ranges $74-100 \%$ for BBS, 66-96\% for mini-BAL and $71-100 \%$ for BPSB. The bilateral, diffuse pattern of the VAP [37, 38] could explain why the diagnostic yield of blinded procedures is similar to fibreoptic techniques [56], although the former have not been validated by post mortem lung examination. Its usefulness seems evident in units with no bronchoscope available $24 \mathrm{~h}$ a day.

The side effects of the blinded invasive techniques, although not completely described, are less important in comparison with fibreoptic bronchoscopic techniques.

Open lung biopsy. Although open lung biopsy (OLB) has not been found to significantly improve the patients management or the clinical evolution, it should be considered as a diagnostic method when less invasive tools of diagnosis have been exhausted [61], (for example, the patient with diffuse pulmonary infiltrate, infectious or not, with no diagnosis by other methods including bronchoscopy). Quantitative culture of the sample is recommended. However, a dissociation between the bacteriological findings and histological features of pneumonia has been reported by some studies [37, 62]. Unfortunately, at this stage the patients are already on antibiotic treatment and therefore, the culture of the lung sample obtained by OLB is frequently sterile. This bacteriological finding is 
consistent with the unspecific diffuse alveolar damage reported by the histological examination.

General anaesthesia is required for OLB. There are two possible surgical approaches: small thoracotomy incision and videothoracoscopy. After the inspection of the lung, the biopsy is performed on the most involved area, usually from the middle lobe (or lingula) or lower lobes. Lung biopsy can be obtained using automatic linear stapling devices. The patients are disconnected from the ventilator when the stapler is applied and reconnected immediately after the biopsy, facilitating the procedure [63].

The rate of complications of OLB varies $4-19 \%$. The most common complications related to OLB are pneumothorax requiring pleural drainage, bleeding and the side-effects associated with anaesthesia or the surgical procedure [64]. The mortality rate does not exceed $0.5 \%$, although most of the studies in the literature do not report any death. Indeed, a recent study has proved the safety of OLB in patients with respiratory failure and receiving mechanical ventilation [65]. However, the choice of OLB as a diagnostic test should take into account the multiple organ failure score, which has proved to be a good predictor of mortality related to this procedure [66]. The diagnostic accuracy of quantitative culture of OLB specimen varies 55-91\% [65]. A negative result in the presence of nonspecific inflammatory changes should draw the attention to noninfectious causes of the pulmonary infiltrate.

\section{Validation of the diagnostic techniques used in ventilator-associated pneumonia}

The validation of the diagnostic techniques in VAP is rather difficult because of the heterogeneity of the gold standard used by the current studies. The more reasonable candidate for a reliable gold standard seems to be the culture of the lung tissue. However, there is strong evidence $[35,37]$ that the bacterial burden has a large variability in lung tissue. In fact, the 1st Consensus Conference [67] on VAP recommended the lung tissue examination, instead of culture, as reference for assessing different diagnostic methods. However, initial or resolution periods of the infection make the distinction between histological pneumonia and other lung processes in critically ill patients difficult [37]. Based on these findings, the best approach for considering a gold standard is probably to take into account both lung histology and tissue culture [38, 63, 68]. The histological criteria of pneumonia should be the presence of a high accumulation of polymorphonuclear leukocytes in the alveoli, along with fibrinous exudate and few erythrocytes [68, 69]. The bacterial growth has to be $\geqslant 10^{3}-10^{4} \mathrm{cfu} \cdot \mathrm{g}$ lung tissue ${ }^{-1}$.

\section{Bacteriological analysis of the respiratory sample}

The analysis of respiratory samples consists basically in microscopic evaluation and quantitative culture. Promising techniques of rapid microbial detection, such as polymerase chain reaction (PCR) and antigen detection, need further studies to confirm their benefits in the current practice of VAP.

\section{Microscopic analysis}

The microscopic analysis of the respiratory samples includes: 1) Evaluation of the alveolar cell population (total and differential cell count): several studies have shown a significant increase in total neutrophilic count in the respiratory samples collected by BAL and PSB in patients with VAP. The mean percentage of neutrophils varies $77-82 \%$ in BAL and is $>50 \%$ in PSB [7, $31,70]$. These findings are consistent with a number of colony forming units in culture which are suggestive for pneumonia. 2) Squamous epithelial cells (SECs) and bronchial ciliated cells (BCCs): the presence of $>1 \%$ SECs in BAL is indicative of oropharyngeal contamination [68, 71]. There is poor evidence about the significance of SECs in PSB, but it appears that their absence or presence in very small amounts $(\leqslant 1$ per field) is a predictor of a good quality PSB sample [27]. The presence of BCCs as a marker of contamination in mechanically ventilated patients has not been thoroughly investigated. 3) Percentage of cells (neutrophils) containing intracellular organisms (ICO) detected in BAL samples: recent studies suggest that ICO detection could be useful for an early diagnosis of pneumonia and the accepted threshold value of infected cells is $\sim 5 \%$; however, the sensitivity of the test varies largely (37$100 \%$ ) [7, 31, 46, 47, 72-76]. 4) Stains for the recognition of organisms: Gram, acid-fast (for mycobacteria), potassium hydroxide (for fungi): there is a good agreement between the findings on the Gram stain of BAL/PSB sample and the results of quantitative cultures [7, 20, 77]. 5) Cytological analysis for alternative diagnosis: pulmonary haemorrhage, carcinoma, opportunistic infection with organisms such as Pneumocystis carinii and cytomegalovirus (CMV). Table 1 summarizes the main criteria to assess the quality of a respiratory tract sample in VAP according to the different sampling methods (ETA, PSB, BAL).

\section{Quantitative culture}

Quantitative culture of respiratory samples are useful to distinguish colonization from infection, based on the assessment of the concentration of organisms present in the respiratory secretions. However, the concentration of organisms necessary to cause pneumonia varies in relation to the virulence of the bacteria and the competence of host defence [45]. Within a clinical context of pneumonia, a bacterial burden has been demonstrated of $\geqslant 10^{4} \mathrm{cfu} \cdot \mathrm{g}$ lung tissue ${ }^{-1}[30,78]$ and $\geqslant 10^{5}$ bacteria $\cdot \mathrm{mL}^{-1}$ exudate [79].

Respiratory samples collected by any method described above are serially diluted and inoculated routinely into blood agar, chocolate agar, CDC agar, buffered charcoal yeast extract agar and Sabouraud medium. Culture plates are incubated at $37^{\circ} \mathrm{C}$ under adequate aerobic and anaerobic conditions and evaluated at 24 and $48 \mathrm{~h}$. The thresholds currently employed for the diagnosis of the pneumonia are the following: ETA samples, $\geqslant 10^{5}-10^{6} \mathrm{cfu} \cdot \mathrm{mL}^{-1}$; blinded methods samples, $\geqslant 10^{3}-10^{4} \mathrm{cfu} \cdot \mathrm{mL}^{-1}$; PSB samples, $\geqslant 10^{3} \mathrm{cfu} \cdot \mathrm{mL}^{-1}$; and BAL samples, $\geqslant 10^{4} \mathrm{cfu} \cdot \mathrm{mL}^{-1}$ (table 1). A bacterial count below the threshold in patients with clinical features of pneumonia should not 
prohibit the antibiotic treatment, whereas it could be an early phase of infection. The routine culture concerns bacteria and fungi. In patients not responding to the antibiotic reatment other possible pathogens should be investigated (i.e. Mycobacterium tuberculosis, P. carinii, CMV, Chlamydia pneumoniae, L. pneumophilia). Susceptibility tests are recommended routinely, if possible by determination of the minimal inhibitory concentration (MIC).

\section{Invasive versus noninvasive techniques for diagnosing ventilator-associated pneumonia}

There is a debate in the literature about using the invasive or noninvasive methods in VAP for collecting an appropriate respiratory sample. This debate has focussed recently on the outcome of patients, which includes length of ICU and hospital stay, mortality and costs.

Main arguments in favour of performing invasive diagnosis techniques in mechanically ventilated patients are as follows: 1) attributable mortality of VAP is $\sim 30 \%$, a fact that requires a more aggressive investigation of patients with VAP [6];2) inadequate antibiotic treatment appears to be the most frequent factor related to a poor prognosis in patients with VAP [80]; 3) the initial empirical treatment is frequently incorrect [81] and the invasive techniques often lead to antibiotic changes; and 4) invasive techniques have no important side-effects or complications.

The arguments against the use of invasive methods (BAL, PSB) in VAP are the following: 1) attributable mortality does not exist when initial empirical antibiotic treatment is adequate [82]; 2) the optimal empirical treatment strategy should be initiated according to the standardization of severity, risk factors, days of mechanical ventilation and related flora [83]; 3 ) the information provided by invasive techniques does not lead to changes in antibiotic treatment if the empirical therapy is appropriately standardized, according to ATS guidelines; 4) the use of invasive techniques does not modify the mortality rate [23, 84]; and finally, 5) invasive techniques, especially BAL, could be associated with important complications such as sepsis-like effects and persistent hypoxaemia.

In the authors opinion, the best approach to solve the present debate should take into consideration only the results of the randomized studies comparing quantitative culture of samples obtained by invasive techniques and ETA. There are only three studies complying with these criteria $[22,23,85]$. SANCHEZNiETO et al. [22] reported that bronchoscopy led to more frequent antibiotic changes and a greater cost of antibiotic therapy, with no change in morbidity and mortality rate. The study of RuIz et al. [23] reported a similar diagnostic yield of invasive and noninvasive techniques, similar mortality rate in the two groups of patients but, in contrast, a significantly higher cost of the microbial investigation when using invasive techniques. Finally, Sole-Violan et al. [85] concluded also that, when empirical antibiotic treatment is appropriately standardized, quantitative culture of samples obtained by invasive techniques does not improve the outcome of VAP in comparison with qualitative culture of samples obtained by noninvasive techniques. The conclusion of these three studies is practically the same: using invasive techniques for diagnosing VAP leads to more antibiotic changes but with no improvement in mortality or morbidity rate and with additional costs.

Controversially, a recent large randomized trial conducted by FAGON et al. [86] found that patients managed by invasive techniques showed a lower mortality at 14 days and less antibiotic use compared to patients diagnosed by clinical criteria and endotracheal aspirate. Nevertheless, it should be mentioned that this study has compared qualitative culture of the ETA with quantitative culture of BAL or PSB, leading therefore to questionable conclusions.

Although quantitative culture of ETA appears to be the more appropriate routine technique in VAP, more severely ill patients or patients not responding to initial empirical antibiotic regimens may potentially benefit from the invasive techniques.

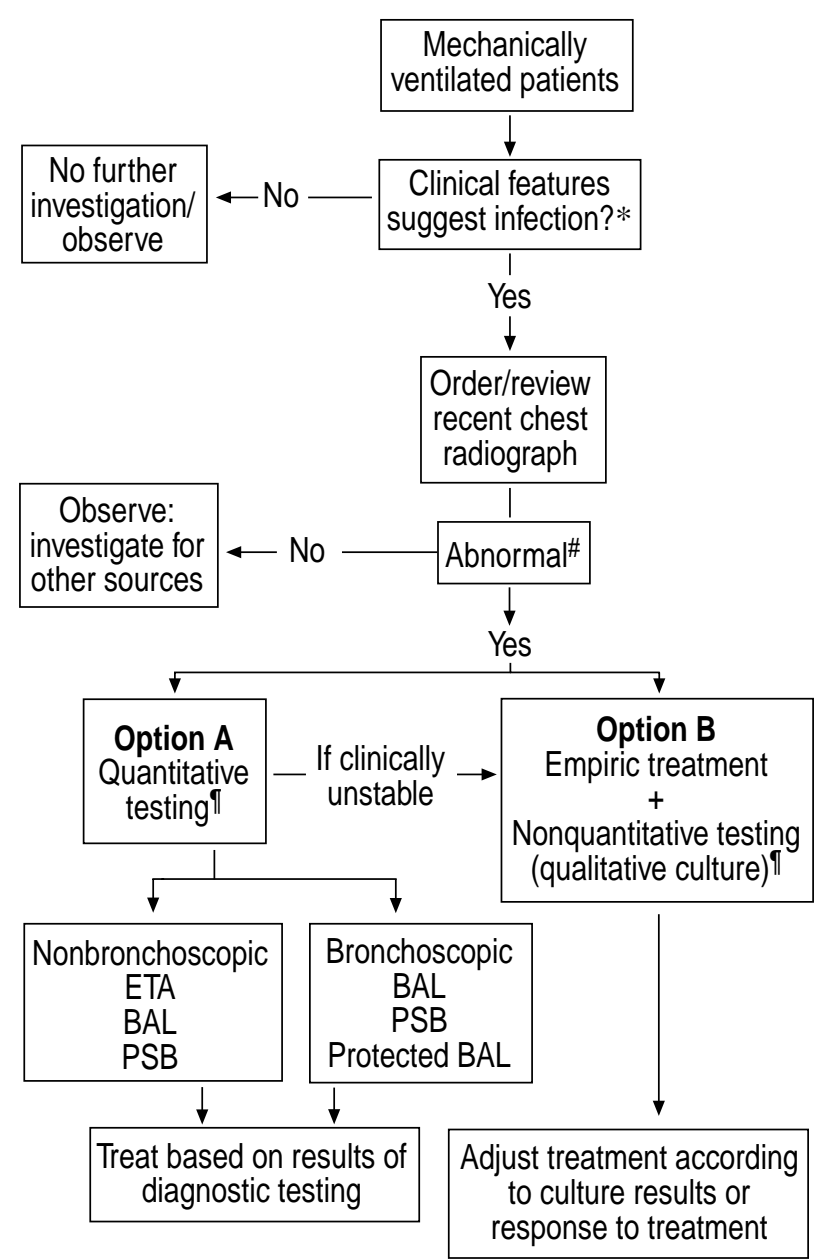

Fig. 1. - Ventilator-associated pneumonia (VAP) diagnostic algorithm. *: two or more of the following criteria: temperature $>38^{\circ} \mathrm{C}$ or $<36^{\circ} \mathrm{C}$, leukocytosis or leukopenia, purulent tracheal secretion, decreased $\mathrm{Pa}, \mathrm{O}_{2}$; \#: radiographic evidence of alveolar infiltrates, air bronchograms, new or worsened infiltrates; $\uparrow$ : there is no definitive evidence to support either option A or B, therefore, the clinician should choose the appropriate test based on its sensitivity and specificity, potential adverse effects, availability and cost; ETA: endotracheal aspirate; BAL: bronchoalveolar lavage; PSB: protected specimen brush. (Adapted from [89]). 
Basically, the following conclusions appear evident: 1) the diagnostic value of the quantitative culture from endotracheal aspirate is similar to that provided by invasive methods (protected specimen brush, bronchoalveolar lavage) [23, 87]; 2) the invasive techniques lead to more changes of the antibiotic treatment but without any improvement of mortality and morbidity rate $[22,23,85]$; and 3$)$ the endotracheal aspirate is less expensive compared to the invasive investigation $[23,88]$. However, further studies are required to establish which is the best approach for the diagnosis of ventilator-associated pneumonia, since the experts' opinions are still divided. For the moment and still needing more evidence from new randomized studies, the clinician is recommended to use the diagnostic algorithm (fig. 1) proposed by the recent evidencebased guidelines for the diagnosis of ventilator-associated pneumonia, which reviewed the most solid studies in the field [89].

\section{References}

1. Rello J, Quintana E, Ausina V, et al. Incidence, etiology and outcome of nosocomial pneumonia in mechanically ventilated patients. Chest 1991; 100: 439-444.

2. Fagon JY, Chastre J, Vuagnat A, Trouillet JL, Novara A, Gibert C. Nosocomial pneumonia and mortality among patients in intensive care units. JAMA 1996; 275: 866-869.

3. Celis R, Torres A, Gatell JM, Almela M, RodriguezRoisin R. Nosocomial pneumonia: A multivariate analysis of risk and prognosis. Chest 1988; 93: 318 324.

4. Rello J, Ausina V, Ricart M, et al. Risk factors for infection by Pseudomonas aeruginosa in patients with ventilator-associated pneumonia. Intensive Care Med 1994; 20: 193-198.

5. American Thoracic Society. Hospital-acquired pneumonia in adults: Diagnosis, assessment, initial therapy, and prevention: A consensus statement. Am J Respir Crit Care Med 1996; 153: 1711-1725.

6. Fagon JY, Chastre J, Hance AJ, Montravers P, Novara A, Gibert C. Nosocomial pneumonia in ventilated patients: A cohort study evaluating attributable mortality and hospital stay. Am J Med 1993; 94: 281288.

7. Pugin J, Auckenthaler R, Mili N, Janssens JP, Lew PD, Suter P. Diagnosis of ventilator associated pneumonia by bacteriologic analysis of bronchoscopic and non-bronchoscopic "blind" bronchoalveolar lavage fluid. Am Rev Respir Dis 1991; 143: 1121-1129.

8. Prod hom G, Leuenberger P, Koerfer J, et al. Nosocomial pneumonia in mechanically ventilated patients receiving antacid, ranitidine, or sucralfate as prophylaxis for stress ulcer. Ann Intern Med 1994; 120: 653662.

9. Inglis TJ, Sproat LJ, Hawkey PM, et al. Staphylococcal pneumonia in ventilated patients: A twelve months review of cases in an intensive care unit. $J$ Infect Dis 1993; 25: 207-210

10. Rello J, Torres A, Ricart M, et al. Ventilator-associated pneumonia by Staphylococcus aureus. comparison of methicillin-resistant and methicillin-sensitive episodes. Am J Respir Crit Care Med 1994; 150: 15451549.
11. Trouillet JL, Chastre J, Vuagnat A, et al. Ventilatorassociated pneumonia caused by potentially drugresistant bacteria. Am Rev Respir Dis 1998; 157: 531539.

12. Silvestri L, Monti Bragadin C, Milanese M, et al. Are most ICU infections really nosocomial? A prospective observational cohort study in mechanichally ventilated patients. J Hosp Infect 1999; 42: 125-133.

13. Rello J, Gallego M, Mariscal D, Sonora R, Valles J. The value of routine microbiologic investigation in the diagnosis of ventilator-associated pneumonia. Am J Respir Crit Care Med 1997; 156: 196-200.

14. Blasi F, Cosentini R. Non invasive methods for the diagnosis of pneumonia. Eur Respir Mon 1997; 3: 157174.

15. Bryan CS, Reynolds KL. Bacteriemic nosocomial pneumonia period analysis of 172 episods from a single metropolitan area. Am Rev Respir Dis 1984; 129: 668-671.

16. Fagon JY, Chastre J, Domart Y, et al. Nosocomial pneumonia in patients receiving continuous mechanical ventilation. Prospective analysis of 52 episodes with use of a protected specimen brush and quantitative culture techniques. Am Rev Respir Dis 1989; 139: 877-884.

17. Luna CM, Videla A, Mattera J, et al. Blood cultures have limited value in predicting severity of illness and as a diagnostic tool in ventilator-associated pneumonia. Chest 1999; 116: 1075-1084.

18. El-Ebiary M, Torres A, González J, Puig de la Bellacasa J, Garcia C, Jimenez de Anta MT. Quantitative cultures of endotracheal aspirates for the diagnosis of ventilator-associated pneumonia. Am J Respir Crit Care Med 1993; 147: 1552-1557.

19. Sauaia A, Moore F, Moore E, et al. Diagnosing pneumonia in mechanically ventilated trauma patients: endotracheal aspirate versus bronchoalveolar lavage. J Trauma 1993; 35: 512-517.

20. Torres A, Puig de la Bellacasa J, Xaubet A, RodriguezRoisin R, Jiménez de Anta MT, Agustí-Vidal A. Diagnostic value of quantitative cultures of bronchoalveolar lavage and telescoping plugged catheters in mechanically ventilated patients with bacterial pneumonia. Am Rev Respir Dis 1989; 140: 306-310.

21. Salata RA, Lederman MM, Shales DM, et al. Diagnosis of nosocomial pneumonia in intubated, intensive care unit patients. Am Rev Respir Dis 1987; 135: 426432.

22. Sanchez-Nieto JM, Torres A, Garcia-Cordoba F, et al. Impact of invasive and noninvasive quantitative culture sampling on outcome of ventilator-associated pneumonia: a pilot study. Am J Respir Crit Care Med 1998; 157: 371-376.

23. Ruiz M, Torres A, Ewig S, et al. Noninvasive versus invasive microbial investigation in ventilator-associated pneumonia: evaluation of outcome. Am $J$ Respir Crit Care Med 2000; 162: 119-125.

24. Lambert R, Vereen L, George R. Comparison of tracheal aspirates and protective brush catheter specimens for identifying pathogenic bacteria in mechanically ventilated patients. Am J Med Sci 1989; 297: 377-382.

25. Shepherd K, Wain J, Brown E, et al. Elastin fibers and the diagnosis of bacterial pneumonia in adult respiratory distress syndrome. Crit Care Med 1995; 23: 1829-1834.

26. Wimberley L, Falling LJ, Bartlett JG. A fiberoptic 
bronchoscopy technique to obtain uncontaminated lower airway secretions for bacterial culture. Am Rev Respir Dis 1979; 119: 337-343.

27. Marquette $\mathrm{CH}$, Wallet $\mathrm{F}$, Neviere $\mathrm{R}$, et al. Diagnostic value of direct examination of the protective specimen brush in ventilator-associated pneumonia. Eur Respir $J$ 1994; 7: 105-113.

28. Niederman MS, Torres A. Bronchoscopy for pneumonia: indications, methodology and clinical application. In: Feinsilver S, Fein AM, eds. Textbook of bronchoscopy. Williams and Wilkins, 1995; pp. 221241.

29. Baughman RP, Thorpe JE, Staneck J, et al. Use of the protective specimen brush in patients with endotracheal or tracheostomy tubes. Chest 1987; 1991: 233-236.

30. Chastre J, Viau F, Brun P, et al. Prospective evaluation of the protected specimen brush for the diagnosis of pulmonary infections in ventilated patients. Am Rev Respir Dis 1984; 130: 924-929.

31. Chastre J, Fagon JY, Soler P, et al. Diagnosis of nosocomial bacterial pneumonia in intubated patients undergoing ventilation: comparison of the usefulness of bronchoalveolar lavage and the protected specimen brush. Am J Med 1988; 85: 499-506.

32. Chastre J, Fagon JY, Bornet-Lesco M, et al. Evaluation of bronchoscopic techniques for the diagnosis of nosocomial pneumonia. Am J Respir Crit Care Med 1995; 152: 231-240.

33. Fagon JY, Chastre J, Hance AJ, et al. Detection of nosocomial lung infection in ventilated patients. Use of a protected specimen brush and quantitative culture techniques in 147 patients. Am Rev Respir Dis 1988; 138: $110-116$

34. Marquette $\mathrm{CH}$, Georges $\mathrm{H}$, Wallet $\mathrm{F}$, et al. Diagnostic efficiency of endotracheal aspirate with quantitative bacterial cultures in intubated patients with suspected pneumonia period. Comparison with the protected specimen brush. Am Rev Respir Dis 1993; 148: 138144.

35. Papazian L, Thomas $\mathrm{P}$, Garbe L, et al. Bronchoscopic or blind sampling techniques for the diagnosis of ventilator associated pneumonia. Am Rev Respir Dis 1995; 152: 1982-1991.

36. Pham LH, Brun-Buisson C, Legrand P, et al. Diagnosis of nosocomial pneumonia in mechanically ventilated patients: comparison of a plugged telescoping catheter with the protected specimen brush. Am Rev Respir Dis 1991; 143: 1055-1061.

37. Fabregas N, Torres A, El-Ebiary M, et al. Histopathologic and microbiologic aspects of ventilator-associated pneumonia. Anesthesiology 1996; 84: 760-771.

38. Rouby JJ, Martin De Lassale E, Poete $\mathrm{P}$, et al. Nosocomial bronchopneumonia in the critically ill. Am Rev Respir Dis 1992; 146: 1059-1066.

39. Montravers P, Fagon JY, Chastre J, et al. Follow-up protected specimen brushes to assess treatment in nosocomial pneumonia. Am Rev Respir Dis 1993; 147: 38-44.

40. Timsit JF, Misset B, Renaud B, Goldstein FW, Carlet J. Effect of previous antimicrobial therapy on the accuracy of the main procedures used to diagnose nosocomial pneumonia in patients who are using ventilation. Chest 1995; 108: 1036-1040.

41. Dreyfuss D, Mier L, Le Bourdelles K, et al. Clinical significance of borderline quantitative protected specimen brush specimen culture results. Am Rev Respir Dis 1993; 147: 946-951.
42. Marquette $\mathrm{CH}$, Herengt F, Mathieu D, Saulnier F, Courcol R, Ramon P. Diagnosis of pneumonia in mechanically ventilated patients. Repeatability of the protected specimen brush. Am Rev Respir Dis 1993; 147: 211-214.

43. Timsit JF, Misset B, Francoual S, et al. Is protected specimen brush reproducible method to diagnose ICUacquired pneumonia. Chest 1993; 104: 104-108.

44. Torres A, El-Ebiary M, González J, Gene A, Rodriguez-Roisin R. Specificity of endotracheal aspiration, protected specimen brush and bronchoalveolar lavage in mechanically ventilated patients. Am J Respir Crit Care Med 1993; 147: 952-957.

45. Meduri GU, Chastre J. The standarization of bronchoscopic techniques for ventilator-associated pneumonia. Chest 1992; 102: 557S-564S.

46. Meduri GU, Beals DH, Maijub AG, Baselski V. Protected bronchoalveolar lavage: A new bronchoscopic technique to retrieve uncontaminated distal airway secretions. Am Rev Respir Dis 1991; 143: 855864.

47. Torres A, El-Ebiary M, Fabregas N, et al. Value of intracellular bacteria detection in the diagnosis of ventilator associated pneumonia. Thorax 1996; 51: 378-384.

48. Torres A, de la Bellacasa JP, Rodriguez RR, Jimenez M, Agusti VA. Diagnostic value of telescoping plugged catheters in mechanically ventilated patients with bacterial pneumonia using the Metras catheter. Am Rev Respir Dis 1988; 138: 117-120.

49. Pugin J, Suter PM. Diagnostic bronchoalveolar lavage in patients with pneumonia produces sepsis-like systemic effects. Intensive Care Med 1992; 18: 6-10.

50. Nelson EM, Wald TC, Bailey K, Wesselius LJ. Intrapulmonary cytokine accumulation following BAL and the role of endotoxin contamination. Chest 1999; 115: 151-157.

51. Montravers P, Gauzit R, Dombret MC, Blanchet F, Desmonts JM. Cardiopulmonary effects of bronchoalveolar lavage in critically ill patients. Chest 1993; 104: 1541-1547.

52. Fraire A, Cooper S, Greenberg S, et al. Transbronchial lung biopsy. Histopathologic and morphometric assessment of diagnostic utility. Chest 1992; 102: 748-752.

53. Burt M, Flye M, Webber B, et al. Prospective evaluation of aspiration needle, cutting needle, transbronchial and open biopsies in chronic infiltrate lung disease. Ann Thoracic Surg 1981; 32: 146-151.

54. Papin TA, Grum CM, Weg JG. Transbronchial biopsy during mechanical ventilation. Chest 1986; 89: 168170.

55. Pincus PS, Kallenbach JM, Hurwitz MD, et al. Transbronchial biopsy during mechanical ventilation. Crit Care Med 1987; 15: 1136-1139.

56. Kollef MH, Bock KR, Richards RD, Hearns ML. The safety and diagnosis accuracy of minibronchoalveolar lavage in patients with suspected ventilator associated pneumonia. Ann Intern Med 1995; 122: 743-748.

57. Marik PE, WJ B. A comparison of bronchoscopic versus blind protected specimen brush sampling in patient with suspected ventilator-associated pneumonia. Chest 1985; 108: 203-207.

58. Leal-Noval SR, Alvaro-Rodriguez E, Murillo-Cabeza F, Garnacho-Montero J, Rey-Perez J, Munoz-Sanchez MA. Diagnostic value of a blind brush in mechanically 
ventilated patients. Intensive Care Med 1992; 18: 410414.

59. Jordá R, Parras F, Ibanñez J, Reina J, Bergadá J, Raurich JM. Diagnosis of nosocomial pneumonia in mechanically ventilated patients by the blind protected telescoping catheter. Intensive Care Med 1993; 19: 377382.

60. Rouby JJ, Rossignon MD, Nicolas $\mathrm{MH}$, et al. A prospective study of protected bronchoalveolar lavage in the diagnosis of nosocomial pneumonia. Anaesthesiology 1989; 71: 179-185.

61. McKenna RJ, Mountain CF, McMurtray MJ. Open lung biopsy in immunocompromised patients. Chest 1987; 91: 639-640.

62. Wermert $\mathrm{D}$, Marquette $\mathrm{CH}$, Copin $\mathrm{MC}$, et al. Influence of pulmonary bacteriology and histology on the yield of diagnostic procedures in ventilatoracquired pneumonia. Am J Respir Crit Care Med 1998; 158: $139-147$

63. Torres A, El-Ebiary M. Invasive diagnostic techniques for pneumonia: protected specimen brush, bronchoalveolar lavage, and lung biopsy methods. Infect Dis Clin North Am 1998; 12: 701-722.

64. Ray JF, Lawton BR, Myers WO. Open lung biopsy: nineteen years experience with 416 consecutive operations. Chest 1976; 69: 43-47.

65. Hill JM, Ratliff JL, Parrot JCW, et al. Pulmonary pathology in acute respiratory insufficiency: Lung biopsy as a diagnostic tool. $J$ Thorac Cardiovasc Surg 1976; 71: 64-71.

66. Flabouris A, Myburgh J. The utility of open lung biopsy in patients requiring mechanical ventilation. Chest 1999; 115: 811-817.

67. Pingleton SK, Fagon JY, Leeper KV. Patient selection for clinical investigation of ventilator-associated pneumonia: criteria for evaluating diagnostic techniques. Chest 1992; 105: 553S-556S.

68. Marquette $\mathrm{CH}$, Copin MC, Wallet F, et al. Diagnostic tests for pneumonia in ventilated patients: Prospective evaluation of diagnostic accuracy using histology as a diagnostic gold standard. Am J Respir Crit Care Med 1995; 151: 1878-1888.

69. Torres A, Fabregas N, Arce Y, Lopez-Boado MA. Histopathology of ventilator-associated pneumonia (VAP) and its clinical implications. Infection 1999; 27: 71-76.

70. Gaussorgues P, Piperno D, Bachmann P, et al. Comparison of nonbronchoscopic bronchoalveolar lavage to open lung biopsy for the bacteriologic diagnosis of pulmonary infections in mechanically ventilated patients. Intensive Care Med 1989; 15: 94-98.

71. Sole-Violan J, Rodriguez de Castro F. Comparison of bronchoscopic diagnostic techniques with histological findings in brain dead organ donors without suspected pneumonia. Thorax 1996; 51: 929-931.

72. Aubas S, Aubas P, Capdevila X, Darbas H, Roustan J, Cailar J. Bronchoalveolar lavage for diagnosing bacterial pneumonia in mechanically ventilated patients. Am J Respir Crit Care Med 1994; 149: 860-866.

73. Barreiro B, Dorca J, Manresa F, et al. Protected bronchoalveolar lavage in the diagnosis of ventilatorassociated pneumonia. Eur Respir J 1996; 9: 1500 1507.

74. Meduri GU, Wunderink RG, Leeper KV Jr, Beals
DH. Management of bacterial pneumonia in ventilated patients. Protected bronchoalveolar lavage as a diagnostic tool. Chest 1992; 101: 500-508.

75. Sole-Violan J, Rodriguez de Castro F, Rey A, MartinGonzalez JC, Cabrera-Navarro P. Usefulness of microscopic examination of intracellular organisms in lavage fluid in ventilator-associated pneumonia. Chest 1994; 106: 889-894.

76. Valles J, Rello J, Fernandez R, et al. Role of bronchoalveolar lavage in mechanically ventilated patients with suspected pneumonia. Eur J Clin Microbiol Infect Dis 1994; 13: 549-558.

77. Chastre J, Fagon JY, Soler P, et al. Quantification of BAL cells containing intracellular bacteria rapidly identifies ventilated patients with nosocomial pneumonia. Chest 1989; 95: 90S-92S.

78. Johanson WG Jr, Seidenfeld JJ, Gomez P, de los Santos R, Coalson JJ. Bacteriologic diagnosis of nosocomial pneumonia following prolonged mechanical ventilation. Am Rev Respir Dis 1988; 137: 259-264.

79. Bartlett J. Invasive diagnostic techniques in pulmonary infection. In: Pennington JE, ed. Respiratory infections: diagnostic and management. Raven Press, 1989.

80. Alvarez-Lerma F, ICU-acquired Pneumonia Study Group. Modification of empiric antibiotic treatment in patients with pneumonia acquired in the intensive care unit. Intensive Care Med 1996; 22: 387-394.

81. Fagon JY, Chastre J, Hance AJ, et al. Evaluation of clinical judgement in the identification and treatment of nosocomial pneumonia in ventilated patients. Chest 1993; 103: 547-553.

82. Papazian L, Bregeon F, Thirion X, et al. Effect of ventilator-associated pneumonia on mortality and morbidity. Am J Respir Crit Care Med 1996; 154: 91-97.

83. Campbell DG, Niederman MS, Broughton W, et al. Guidelines for the initial management of adults with hospital-acquired pneumonia. Am J Respir Crit Care Med 1996; 153: 1711-1725.

84. Luna CM, Vujacich P, Niederman MS. Impact of bronchoalveolar lavage data on therapy and outcome of VAP. Chest 1997; 111: 676-687.

85. Sole-Violan J, Arroyo Fernandez J, Bordes Benitez A, Cardenosa Cendrero JA, Rodriguez de Castro F. Impact of quantitative invasive diagnostic techniques in the management of outcome of mechanically ventilated patients with suspected pneumonia. Crit Care Med 2000; 28: 2737-2741.

86. Fagon JY, Chastre J, Wolff M. Invasive and noninvasive strategies for management of suspected ventilator-associated pneumonia. Ann Intern Med 2000; 132: 612-630.

87. Timsit JF, Chevret S, Valcke J, et al. Mortality of nosocomial pneumonia in ventilated patients: Influence of diagnostic tools. Am J Respir Crit Care Med 1996; 154: 116-123.

88. Flanagan PG. Diagnosis of ventilator-associated pneumonia. J Hosp Infect 1999; 41: 87-99.

89. Grossman R, Baughman RP, Campbell GD, et al. Evidence-based assessment of diagnostic tests for ventilator-associated pneumonia: report of the clinical practice guideline panel. Chest 2000; 117: 177-218. 